\title{
Synthesized mesoporous silica and calcium aluminate cement fillers increased the fluoride recharge and lactic acid neutralizing ability of a resin-based pit and fissure sealant
}

\author{
Atikom SURINTANASARN ${ }^{1}$, Krisana SIRALERTMUKUL ${ }^{2}$ and Niyom THAMRONGANANSKUL ${ }^{1}$ \\ ${ }^{1}$ Department of Prosthodontics, Faculty of Dentistry, Chulalongkorn University, 34 Henri-Dunant Rd., Pathumwan, Bangkok 10330, Thailand \\ ${ }^{2}$ Metallurgy and Materials Science Research Institute, Chulalongkorn University, Soi Chulalongkorn 12, Phayathai Rd., Pathumwan, Bangkok 10330, \\ Thailand \\ Corresponding author, Niyom THAMRONGANANSKUL; E-mail: niyom.t@chula.ac.th
}

\begin{abstract}
This study evaluated the effect of different types of filler in a resin-based pit and fissure sealant on fluoride release, recharge, and lactic acid neutralization. Resin-based sealant was incorporated with $5 \% \mathrm{w} / \mathrm{w}$ of the following fillers: calcium aluminate cement (CAC), synthesized mesoporous silica (SI), a CAC and SI mixture (CAC+SI), glass-ionomer powder (GIC), and acetic acid-treated GIC (GICA). Sealant without filler served as control. The samples were immersed in deionized water or a lactic acid solution and the concentration of fluoride in the water, before and after fluoride recharge, and the lactic acid $\mathrm{pH}$ change, respectively, were determined. The $\mathrm{CAC}+\mathrm{SI}$ group demonstrated the highest fluoride release after being recharged with fluoride gel. The CAC+SI group also demonstrated increased lactic acid $\mathrm{pH}$. These findings suggest that a resin-based sealant containing synthesized mesoporous silica and calcium aluminate cement may enhance remineralization due to fluoride release and higher $\mathrm{pH}$.
\end{abstract}

Keywords: Calcium aluminate cement, Fluoride recharge, Fluoride release, Mesoporous silica, Pit and fissure sealant

\section{INTRODUCTION}

Pit and fissure sealants are materials applied to the pits and fissures of dental caries-susceptible teeth for occlusal caries prevention. Most resin sealants are based on Bis-GMA due to high retention rate $^{1,2)}$. In addition to resin-based sealants, glass-ionomer materials are also used as pit and fissure sealants. An important advantage of a glass-ionomer over a conventional resin sealant is that it can release fluoride ${ }^{3)}$.

To overcome the limitations of the low-retention rate of glass-ionomer and the lack of fluoride release from resin-based materials, resin-based sealants containing fluoride have been introduced. However, long-term benefit has not been found due to the short fluoride releasing period of these materials or known as the burst effect ${ }^{4)}$. Moreover, it is suggested that the fluoride recharge ability of a material is more important than that of fluoride release alone ${ }^{5)}$. Glass-ionomer sealants, which have a high rate of becoming dislodged, demonstrate high fluoride release and recharge properties but resin materials cannot recharge with fluoride ${ }^{6,7)}$.

Calcium aluminate cements have mechanical properties that allow them to be used as bioactive direct restorative materials ${ }^{8)}$. These materials also show potential for use for defluoridation of water ${ }^{9}$. The mechanisms of fluoride adsorption of these materials are physisorption, chemisorption, or both ${ }^{10)}$. Fluoride adsorbed via physisorption is possibly available for release when a calcium aluminate cement is incorporated into a resin-based material.

Mesoporous silica materials possess a high wellordered honeycomb-like pore structure and large surface area. This honeycomb-like structure with numerous empty channels can absorb and encapsulate relatively large amounts of molecules ${ }^{11)}$. However, the fluoride release and recharge capability of a dental material using mesoporous silica as a filler have not been investigated.

Many studies have examined the fluoride release and recharge ability of conventional materials used as pit and fissure sealants. However, there has been no report on the effect of adding a material or a combination of materials to conventional pit and fissure sealants to provide fluoride release and fluoride recharge capabilities. The aim of this study was to evaluate the addition of materials that have the potential for fluoride release and fluoride recharge to resin-based pit and fissure sealant that has a high retention rate. This study compared the fluoride release and recharge abilities of a conventional resin-based sealant and resinbased sealants incorporated with (1) calcium aluminate cement (CAC), (2) synthesized mesoporous silica (SI), (3) a mixture of calcium aluminate cement and synthesized mesoporous silica (CAC+SI), (4) unmodified glassionomer powder (GIC), and (5) acetic acid-modified glass-ionomer powder (GICA) for possible application of these materials as fillers in resin-based pit and fissure sealants. The ability of these materials to neutralize lactic acid was also examined.

\section{MATERIALS AND METHODS}

Mesoporous silica synthesis

The rice hull ash used for this study was obtained from a local business in Ayutthaya, Thailand. The rice hull ash had been burned during rice manufacturing. The obtained rice hull ash was burned at $600^{\circ} \mathrm{C}$ for $3 \mathrm{~h}$ to ensure complete combustion. 
Mesoporous silica was extracted from the rice hull ash using a method adapted from that of Kalapathy et $a l .{ }^{12)}$. The rice hull ash was washed with hydrochloric acid $(\mathrm{HCl})$ to remove other minerals prior to the silica extraction process. Ten grams of rice hull ash were suspended in $60 \mathrm{~mL}$ of distilled water. The $\mathrm{pH}$ was adjusted using $1 \mathrm{~N} \mathrm{HCl}$ until the $\mathrm{pH}$ decreased to 7 . The suspension was stirred for $120 \mathrm{~min}$ and then filtered through a Whatman grade 42 ashless filter paper under vacuum. The residue was then washed with $100 \mathrm{~mL}$ of distilled water through filter paper. This residue was used for the mesoporous silica extraction.

The washed rice hull ash residue was suspended in $60 \mathrm{~mL}$ of $1 \mathrm{~N}$ sodium hydroxide $(\mathrm{NaOH})$ and boiled with stirring at $100^{\circ} \mathrm{C}$ to dissolve the silica and produce a sodium silicate solution. The suspension was filtered through a Whatman grade 42 ashless filter paper and then washed with $100 \mathrm{~mL}$ of boiling water. After $30 \mathrm{~min}$, the filtered solution was titrated with $1 \mathrm{~N} \mathrm{HCl}$ to $\mathrm{pH} 7$. The neutral solution slowly gelled and was allowed to age for $18 \mathrm{~h}$. After aging, $100 \mathrm{~mL}$ of distilled water was added to the gel and the mixture was stirred for $15 \mathrm{~min}$ to crush the gel into slurry. The slurry was then divided into two equal parts that were centrifuged at 2,500 rpm for $15 \mathrm{~min}$. The supernatant was discarded and the washing step was repeated. After centrifuging again, the gel was collected and dried for $12 \mathrm{~h}$ at $80^{\circ} \mathrm{C}$. The dried gel was ground and washed with distilled water and filtered through filter paper before being dried at $80^{\circ} \mathrm{C}$ and ground. The particles were sieved $(<45 \mu \mathrm{m})$ prior to use. This synthesized filler was used in the SI group.

\section{Additional filler preparation}

Conventional glass-ionomer cement powder (GC Fuji IX Gold label, GC, Tokyo, Japan) was suspended in a polyethylene bottle containing a $4 \%$ acetic acid solution for $24 \mathrm{~h}$. The glass-ionomer cement powder in acetic acid solution was filtered through Whatman grade 42 ashless filter paper under vacuum and washed thoroughly using distilled water. After the powder was filtered and dried in a desiccator for $24 \mathrm{~h}$, it was milled and sieved ( $<45$ $\mu \mathrm{m})$ prior to use. Powder without acid treatment was used in the GIC group and the acid-treated powder was used in the GICA group.

Calcium aluminate powder (CA-25R, Almatis, Rotterdam, The Netherlands) was mixed with distilled water (the water-cement ratio was 0.6) and allowed to set for $90 \mathrm{~min}$. After setting, the cement was dried at $100^{\circ} \mathrm{C}$ for $2 \mathrm{~h}$, milled for $2 \mathrm{~h}$, and then sieved $(<45 \mu \mathrm{m})$ before use in the CAC group. Equal amounts of the SI and $\mathrm{CAC}$ filler were mixed together and used in the $\mathrm{CAC}+\mathrm{SI}$ group.

\section{Scanning electron microscopy (SEM)}

The morphology of the filler particles was observed using an ultra-high resolution Schottky field emission scanning electron microscope (JSM-7610F, JEOL, Tokyo, Japan). The samples were platinum coated by a rotary pumped sputter coater (Quorum Q150R S, Quorum Technologies, East Sussex, UK) before SEM observations.

\section{Specimen preparation}

A 6 -mL bottle of resin-based pit and fissure sealant (Concise Light Cured White Sealant, 3M ESPE, St. Paul, MN, USA) was used as the base sealant in this study. For each filler in this study, $5 \% \mathrm{w} / \mathrm{w}$ of filler was added to the sealant and mixed for $60 \mathrm{~s}$. The procedure was performed in an amber plastic chamber to block visible light that could affect the polymerization of the light-curing material. The weight proportions of filler to pit and fissure sealant were chosen to achieve a suitable viscosity of the experimental sealant. The viscosity should not markedly increase because of the difficulty when handling the material during sealant placement. In the control group, sealant alone was placed in the chamber and stirred using a disposable brush tip for $60 \mathrm{~s}$.

Twenty specimens of each group were prepared in a plastic mold (10 $\mathrm{mm}$ diameter and $1 \mathrm{~mm}$ deep). A transparent polyester film $(0.15 \mathrm{~mm}$ thick $)$ was placed on a 1-mm-thick clear glass slide and the mold was then placed over the film. The pit and fissure sealant were prepared as described above, and were slowly placed into the mold, slightly overfilling it. A second polyester film was placed on the mold followed by a second glass slide and pressed with a constant $1-\mathrm{kg}$ weight to extrude the excess cement. A round weight tip was used to allow exposure of the specimen to the curing light. This step resulted in a homogeneous specimen with a smooth surface and could prevent the formation of an oxygen inhibited layer (Fig. 1).

An LED light curing unit with a 10 -mm-diameter light guide (Elipar Freelight 2, 3M ESPE) was used for light activation. The specimens were light activated for $20 \mathrm{~s}$ per section. Irradiation was initially performed around the weight for seven overlapping sections and then the weight was removed before the central

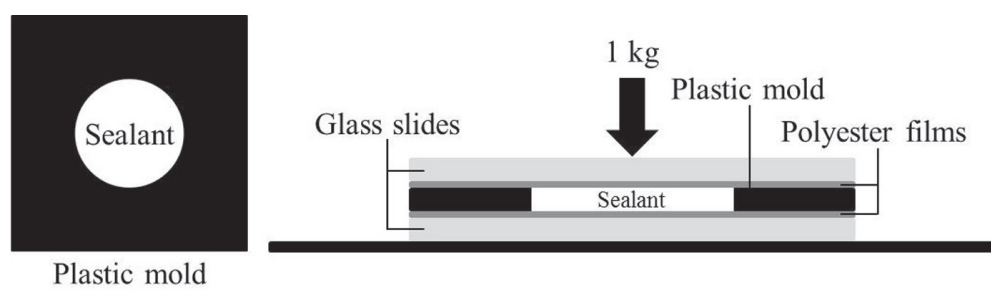

Fig. 1 Specimen prepared in a plastic mold. 


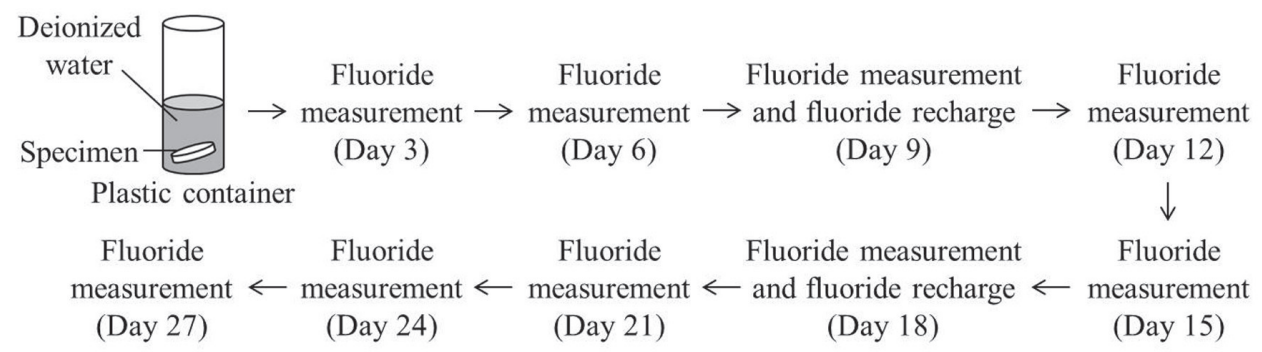

Fig. 2 The fluoride measurement and recharge experimental procedure.

specimen section was irradiated. The opposite side of the specimen was pressed and similarly irradiated. Therefore, the specimen received eight overlapping sections of light activation on each side. After light curing, the specimens were gently removed from the plastic molds and immediately wet polished on each side with 600-grit silicon carbide paper for $10 \mathrm{~s}$.

\section{Fluoride release and recharge ability measurement}

Ten specimens for each group were individually stored in $3 \mathrm{~mL}$ of deionized water in a plastic container at $37^{\circ} \mathrm{C}$. The fluoride concentration of the solution was measured after $72 \mathrm{~h}$ and then every 3 days using a fluoride selective electrode (Orion 9609BNWP, Thermo Scientific, Beverly, MA, USA) coupled to an electrochemistry benchtop meter (Orion Versa Star, Thermo Scientific). One milliliter of the solution was pipetted into a new plastic container and $0.1 \mathrm{~mL}$ of Total Ionic Strength Adjustment Buffer (TISAB III, Thermo Scientific) was added before measurement. The meter was calibrated so that the fluoride readings were based on a calibration curve derived using 1, 0.1, and $0.01 \mathrm{ppm}$ fluoride standard solutions (Certipur, Merck, Darmstadt, Germany). After measurement, each specimen was rinsed with deionized water, cleaned in $50 \mathrm{~mL}$ of deionized water using an ultrasonic bath for $1 \mathrm{~min}$, and then stored in $3 \mathrm{~mL}$ of fresh deionized water in a new plastic container. The experimental procedure of fluoride release and recharge from day $3-27$ is shown in Fig. 2.

To determine the fluoride recharge ability of the specimens, each specimen was individually soaked in $2 \mathrm{~mL}$ of acidulated phosphate fluoride (APF) gel (60 Second Taste Gel, Pascal, Bellevue, WA, USA) in a plastic tube for 4 min on day 9 and day 18 after taking fluoride measurements. The APF gel contained 2.72\% w/v sodium fluoride, generating $1.23 \% \mathrm{w} / \mathrm{w}$ fluoride ions. After soaking in the fluoride gel, each specimen was rinsed with deionized water and cleaned in $50 \mathrm{~mL}$ of deionized water using an ultrasonic bath for $1 \mathrm{~min}$ and then stored in $3 \mathrm{~mL}$ of fresh deionized water in a new plastic container.

\section{Lactic acid neutralizing ability measurement}

Ten specimens for each group, prepared as described above, were stored in individual containers in $2 \mathrm{~mL}$ of deionized water at $37^{\circ} \mathrm{C}$ for $24 \mathrm{~h}$. Lactic acid at a concentration of $0.0002 \mathrm{~mol} / \mathrm{L}$ was freshly prepared ${ }^{13)}$. Each specimen was stored in a plastic container with 2 $\mathrm{mL}$ of the lactic acid solution for $24 \mathrm{~h}$. Two milliliter of the lactic acid solution alone was placed in 10 containers as the control group. After $24 \mathrm{~h}$, the $\mathrm{pH}$ of the test solutions and controls were measured using a pH meter (Orion 420A, Orion Research, Boston, MA, USA) that was calibrated at $\mathrm{pH} 4.00$ and 7.00 immediately before use.

\section{Statistical analysis}

The differences of fluoride release and $\mathrm{pH}$ between the groups on each experimental day were statistically analyzed using one-way ANOVA or the independent $t$-test (SPSS version 22) at a significance level of 0.05 . Data was also evaluated using the Bonferroni post hoc test when equal variances were assumed or the Tamhane's T2 post hoc test when equal variances were not assumed. The differences in fluoride release between experimental days were evaluated using the paired $t$-test.

\section{RESULTS}

The filler particle surface morphology was evaluated using SEM (Fig. 3). The GIC filler demonstrated irregular-shaped particles with a smooth surface (Fig. $3 \mathrm{~A})$, however, the particle surface appeared rough after acetic acid treatment (GICA) (Fig. 3B). The irregular surface of the SI filler appeared as a clumping of fine cubic-shaped particles with a particle size of about $100 \mathrm{~nm}$ into agglomerates (Fig. 3C). The CAC filler demonstrated a gel-like structure with micro-tunnels on the surface (Fig. 3D).

The amount of fluoride released from each material is shown in Table 1 and Fig. 4. At day 3 and 6, initial fluoride release was only found in the GIC and GICA groups with the released fluoride in these groups returning to baseline level by day 9 . In these groups, a significant decrease in fluoride release was found at day 6 compared with day 3. GICA released significantly higher fluoride level at day 6 compared with the GIC group, however, a significant difference was not found at day 3 between these groups. After recharging at day 9 and 18, increased fluoride release was found at day 12 and 21 and the fluoride level decreased to baseline 


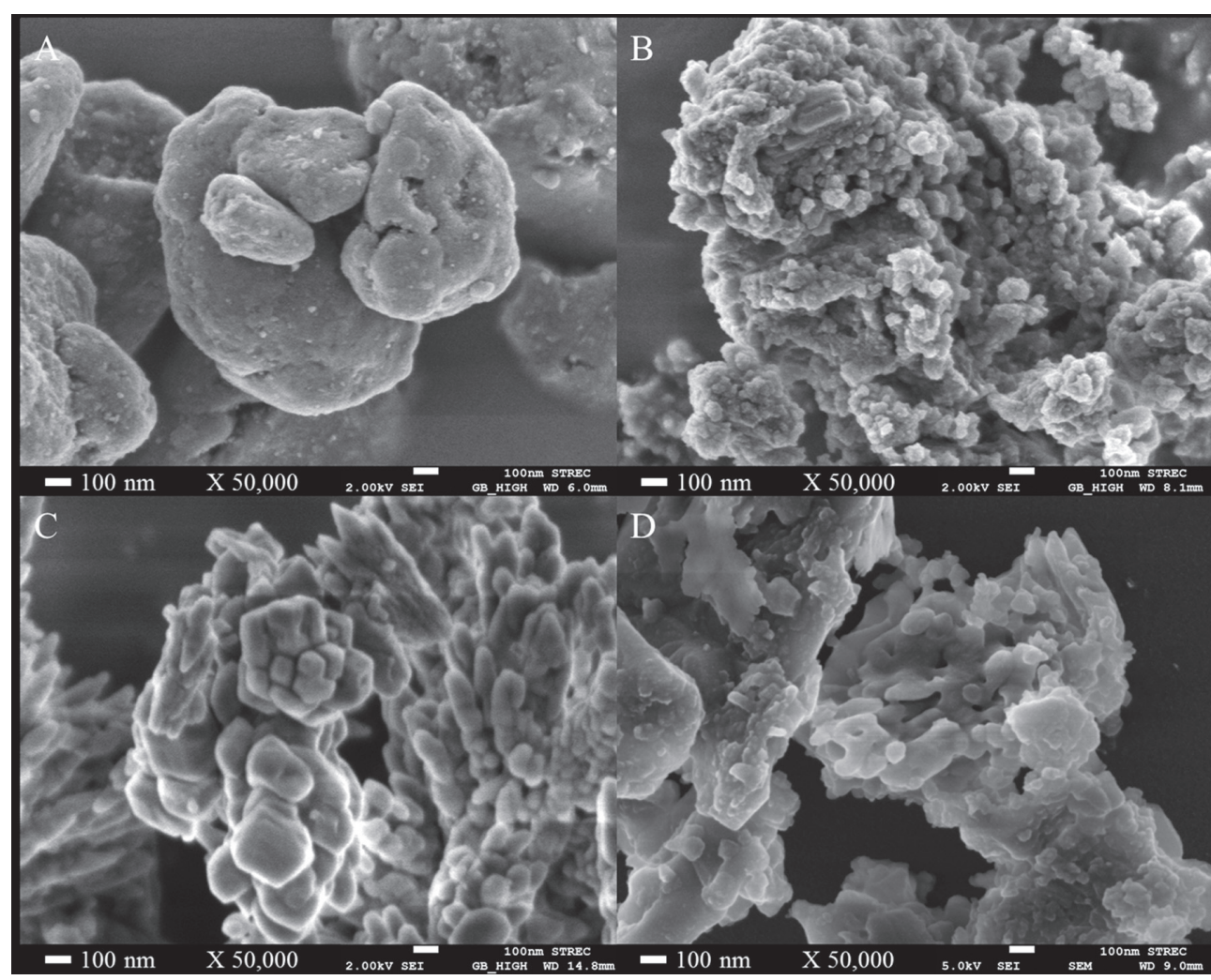

Fig. 3 SEM images of the filler particles.

(a) GIC filler, (b) GICA filler, (c) SI filler, and (d) CAC filler.

Table 1 Fluoride release (ppm)

\begin{tabular}{|c|c|c|c|c|c|c|c|c|c|}
\hline Group & Day 3 & Day 6 & Day 9 & Day 12 & Day 15 & Day 18 & Day 21 & Day 24 & Day 27 \\
\hline Control & ND & ND & ND & ND & ND & ND & ND & ND & ND \\
\hline CAC & ND & ND & $\mathrm{ND}$ & $\begin{array}{l}0.1064^{c} \\
(0.0096)\end{array}$ & $\begin{array}{c}0.0224^{a *} \\
(0.0022)\end{array}$ & ND & $\begin{array}{l}0.0818^{\mathrm{c}} \\
(0.0121)\end{array}$ & ND & ND \\
\hline SI & ND & ND & ND & $\begin{array}{l}0.1151^{\mathrm{c}} \\
(0.0049)\end{array}$ & ND & ND & $\begin{array}{l}0.0949^{\mathrm{c}} \\
(0.0031)\end{array}$ & ND & ND \\
\hline $\mathrm{CAC}+\mathrm{SI}$ & ND & ND & ND & $\begin{array}{l}0.3073^{\mathrm{d}} \\
(0.0227)\end{array}$ & $\begin{array}{c}0.0219^{a *} \\
(0.0025)\end{array}$ & ND & $\begin{array}{l}0.1848^{d} \\
(0.0089)\end{array}$ & TR & ND \\
\hline GIC & $\begin{array}{l}0.1095^{\mathrm{a}} \\
(0.0064)\end{array}$ & $\begin{array}{c}0.0478^{a *} \\
(0.0037)\end{array}$ & ND & $\begin{array}{l}0.0374^{\mathrm{a}} \\
(0.0029)\end{array}$ & ND & ND & $\begin{array}{l}0.0317^{\mathrm{a}} \\
(0.0029)\end{array}$ & ND & ND \\
\hline GICA & $\begin{array}{l}0.1062^{a} \\
(0.0049)\end{array}$ & $\begin{array}{c}0.0554^{\mathrm{b} *} \\
(0.0043)\end{array}$ & ND & $\begin{array}{l}0.0794^{\mathrm{b}} \\
(0.0039)\end{array}$ & ND & ND & $\begin{array}{l}0.0505^{b} \\
(0.0028)\end{array}$ & ND & ND \\
\hline
\end{tabular}

Mean (SD)

Values with the same letters in the same column are not significantly different $(p>0.05)$ (a=lowest values).

ND: Not detectable (less than $0.01 \mathrm{ppm}$ )

TR: Trace (more than or equal to $0.01 \mathrm{ppm}$ but less than $0.02 \mathrm{ppm}$ )

*: significantly different from the previous experimental day $(p<0.05)$

by day 15 and 24, in both groups. At day 12 and 21, the GICA group released significantly more fluoride compared with the GIC group.
The control group did not demonstrate significant differences in fluoride release before or after recharge throughout this study. The initial fluoride release in the 


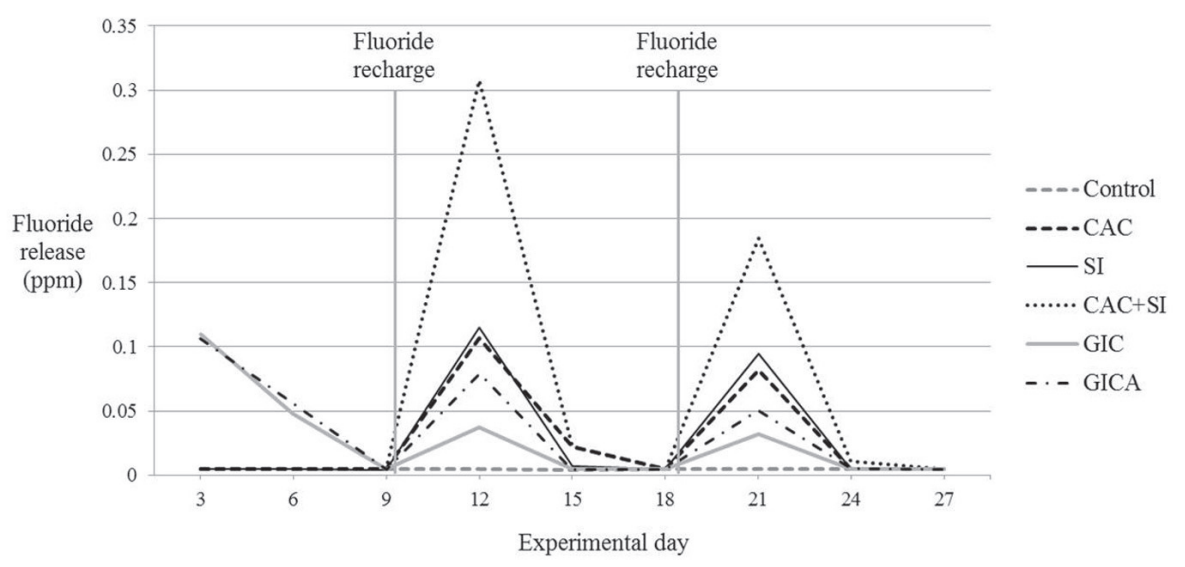

Fig. 4 Fluoride release from the test specimens.

Table 2 Mean lactic acid solution pH change after $24 \mathrm{~h}$

\begin{tabular}{lccc}
\hline \multicolumn{1}{c}{ Group } & Initial pH & pH after $24 \mathrm{~h}$ & $\mathrm{pH}$ difference \\
\hline No specimen & $3.77^{\mathrm{a}}(0.03)$ & $3.78^{\mathrm{a}}(0.03)$ & $0.01^{\mathrm{a}}(0.02)$ \\
Control & $3.77^{\mathrm{a}}(0.03)$ & $3.77^{\mathrm{a}}(0.03)$ & $0.00^{\mathrm{a}}(0.03)$ \\
CAC & $3.77^{\mathrm{a}}(0.02)$ & $4.48^{\mathrm{d}}(0.11)$ & $0.71^{\mathrm{d}}(0.11)$ \\
SI & $3.77^{\mathrm{a}}(0.02)$ & $4.21^{\mathrm{b}}(0.03)$ & $0.45^{\mathrm{b}}(0.03)$ \\
CAC+SI & $3.77^{\mathrm{a}}(0.03)$ & $4.39^{\mathrm{c}, \mathrm{d}}(0.06)$ & $0.61^{\mathrm{d}}(0.06)$ \\
GIC & $3.77^{\mathrm{a}}(0.02)$ & $4.36^{\mathrm{c}, \mathrm{d}}(0.04)$ & $0.59^{\mathrm{c}, \mathrm{d}}(0.05)$ \\
GICA & $3.78^{\mathrm{a}}(0.03)$ & $4.30^{\mathrm{c}}(0.05)$ & $0.52^{\mathrm{c}}(0.05)$ \\
\hline
\end{tabular}

Mean (SD)

Values with the same letters in the same column are not significantly different $(p>0.05)$ (a=lowest values).

CAC, SI, and CAC+SI groups was similar to baseline, however, fluoride release was found after these groups were recharged at day 9 and 18. After being recharged, the CAC+SI group showed the highest fluoride release at day $12,15,21$, and 24 . Although the mean fluoride release in the CAC+SI group at day 24 was 0.0106 ppm, it was reported as a trace level of fluoride release because it was out of the measurement range of the standard curve. However, nine days after each recharge at day 9 and 18, the fluoride level decreased to baseline in the CAC+SI group by day 18 and day 27, respectively.

The results for the $\mathrm{pH}$ change in the lactic acid solutions after $24 \mathrm{~h}$ for each group are shown in Table 2 . The $\mathrm{pH}$ of the solutions in the sealant with filler groups increased after $24 \mathrm{~h}$. The highest significant difference between the test and blank control was found in the CAC group followed by the $\mathrm{CAC}+\mathrm{SI}$ and $\mathrm{GIC}$ groups.

\section{DISCUSSION}

Secondary caries is a common problem after tooth pits and fissures were sealed with a resin-based sealant.
Numerous studies have investigated the prevention of secondary caries development beneath pit and fissure sealants ${ }^{14,15)}$. Remineralization of demineralized tooth structure and acid neutralization are strategies to inhibit secondary caries ${ }^{14}$. Generally, studies of dental caries indicate that fluoride-containing sealants reduce the amount of tooth demineralization adjacent to the material ${ }^{16,17)}$. Another strategy to prevent secondary caries is to develop acid neutralizing materials. A material with $\mathrm{pH}$ stabilizing properties neutralizes the acidic $\mathrm{pH}$ of the oral environment and maintain it at levels where demineralization will be inhibited ${ }^{18)}$.

Fluoride-containing resin sealants release a slight amount of fluoride compared with that of a conventional sealant ${ }^{19)}$. There are two main methods to incorporate fluoride into a pit and fissure sealant. First, soluble fluoride salts are added to unpolymerized resin. When the sealant is applied and polymerized, fluoride ions slowly dissolve in the oral cavity. High amounts of fluoride are released during the first two days, and the release subsequently tapers off. The amount of released fluoride then decreases by approximately one-half 
in three days. This release pattern is called the burst effect ${ }^{4}$. Second, an anion exchange system, to avoid the dissolution of the fluoride salt from the pit and fissure sealant, is used to solve this problem. In this method, an organic fluoride compound is chemically bonded to the resin polymer ${ }^{20}$. Concise sealant was used in our study as a representative of resin-based sealants because it is commonly used as the control material in sealant studies ${ }^{21,22)}$. Conventional resin-based sealant normally does not demonstrate fluoride recharge as demonstrated by our control group results ${ }^{6,7)}$. However, some studies found that resin-based materials can recharge low amounts of fluoride ${ }^{23,24)}$. Fluoride in the surrounding water after recharge is probably due to the release of surface-retained fluoride, rather than fluoride being incorporated into the sealant ${ }^{24)}$. The different findings from our study and other studies may result from different methods of rinsing and cleaning the material in water after fluoride recharge.

Fluoride in the blank control group (the solution of deionized water and TISAB) was also measured. The mean fluoride value of this group was similar to that of the resin-based sealant in deionized water group. Our results are in agreement with previous studies showing that resin-based materials do not have fluoride recharge ability ${ }^{6,7)}$. Because the fluoride calibration curve used in our study had its lowest calibration point at 0.01 ppm, fluoride levels between 0.00 and 0.01 could not be evaluated. Thus, the data in this range was classified as not detectable (ND) and the data that was less than 0.02 ppm but greater than ND was reported as trace (TR). The ND and TR data were not statistically analyzed because they were out of the measurement range of the selective electrode.

Fluoride release without charging was only found in the GIC and GICA groups. These materials contain intrinsic fluoride, because fluoride is added to reduce the materials' melting point during the manufacturing process ${ }^{25}$. The initial high level of fluoride release agrees with previous studies and is due to the burst effect from the fluoro-alumino silicate glass filler in the GIC group and from the glass particles as they are dissolved by dilute acetic during surface treatment ${ }^{26,27}$. In the present study, fluoride from the burst effect was found in the GIC and GICA groups at the first 2 measurement days that decreased with time to a baseline level by day 9 . However, the resin sealant with other fillers did not show an initial fluoride burst effect because there were not any fluoride-containing components in these materials that would be the source of fluoride or intrinsic fluoride in these fillers ${ }^{28}$.

The fluoride recharge ability of a sealant is also important and this ability was found in all groups with incorporated filler. Fluoride recharge was detected in all groups, except for the control group, with the CAC+SI group demonstrating greater release compared with the other groups after fluoride recharge. Then, the fluoride release rate of these materials decreased and stabilized. However, the CAC+SI group had a significantly higher rate of fluoride release when measured 6 days later compared with the other groups. In the glassionomer filler (GIC and GICA) groups, the GICA group demonstrated a higher fluoride release compared with that of the GIC group after the first and second recharge. In a previous study, glass-ionomer plus acetic acid had a higher cement compressive strength after storage because of the growth of a hydrated silicate phase or silica gel that is believed to occur in the secondary phase of setting ${ }^{29,30)}$. Silica gel formed by dilute acid is the only difference between the GIC and GICA fillers. Acetic acid was used in the present study as a surface treatment agent because a previous study showed that acid treatment created silica ge ${ }^{29)}$. The surface roughness seen in the GICA particle SEM images may be due to the formation of this thin silica gel layer on the surface of the glass core. This layer could serve as a reservoir for fluoride ions after fluoride recharge because seed-like inclusions were found in the silica gel layers after the depletion of ions from the surface of the glass core ${ }^{31,32)}$. The use of a $4 \%$ acetic acid solution as a corrosive medium was based on the method of ISO 6872 standard $^{333}$. Acetic acid is believed to be corrosive enough to form a soluble complex on the surface of dental ceramic ${ }^{34)}$.

Fluoride-releasing sealants can recharge their fluoride content when exposed to fluoride such as fluoride gel, fluoride mouthwash, and toothpaste in the oral environment ${ }^{35}$. A higher fluoride recharge capability was normally found in materials with high fluoride release and our results finding higher fluoride recharge in the glass-ionomer groups is supported by those of previous studies ${ }^{35-37}$. Notably, we found that the sealant groups that did not initially demonstrate fluoride release could recharge a high level of fluoride. The CAC+SI group specimens did not initially release fluoride; however, they released more fluoride compared with the conventional and acid-treated glass-ionomer cements after recharge.

Mesoporous silica has received attention due to wide applications in catalysis, optical devices, sensors, separations, and drug delivery. Moreover, it can be used as a host material to confine desired molecules due to extremely high surface area combined with a large and uniform pore $\operatorname{size}^{38}$. Calcium aluminate powder reacts with water in a complex hydration process. After setting, calcium aluminate cement is more porous compared with amalgam and resin composite. The highest porosity level is found in calcium aluminate cement, followed by glassionomer cement ${ }^{39}$. The porosity of calcium aluminate cement and the rough surface of silica, as illustrated in our SEM micrographs, could have a major influence on their fluoride recharge properties. Higher porosity allows greater fluoride diffusion into the material ${ }^{35}$. Restorative materials with a high fluoride release, such as glass-ionomer cement and compomer, generally have low mechanical properties ${ }^{35,40}$. However, a resin-based material containing active filler in this study seems to be mechanically stronger than these materials with lower resin content.

In our study, mesoporous silica and calcium aluminate cement each increased the fluoride recharge 
ability of the sealant due to their porous and rough surface and the combination of both fillers dramatically increased this ability. Calcium aluminate has potential to defluoridate industrial wastewater. The uptake of fluoride ions by calcium aluminate is likely due to its due to a combination of both physisorption and chemisorption $^{9)}$. However, the fluoride released from calcium aluminate is only due to physisorption because chemisorbed fluoride cannot be released. The combination of mesoporous silica and calcium aluminate cement may generate filler with different size of pores and surface roughness that might act as fluoride ion reservoirs for each other.

We found that after $24 \mathrm{~h}$, the groups with incorporated filler demonstrated a lactic acid solution $\mathrm{pH}$ change ranging from 0.45 to 0.71 . These results indicate that all the fillers evaluated could neutralize a lactic acid solution and increase the $\mathrm{pH}$ of the solution after storage. Lactic acid can erode glass-ionomer, however, this disadvantage was accompanied by an increase in the $\mathrm{pH}$ of the acid solution ${ }^{13,41)}$. The results of our study confirmed the findings of previous studies showing that glass-ionomer material increased the $\mathrm{pH}$ of a lactic solution ${ }^{13,42)}$. In agreement with previous studies, we determined that calcium aluminate cement and silica filler also increase the $\mathrm{pH}$ of an acid solution $^{43,44)}$. Higher $\mathrm{pH}$ tends to reduce demineralization and stimulate remineralization, resulting in a reduced prevalence of dental caries ${ }^{13,42)}$.

The CAC group showed the highest neutralizing ability followed by the CAC+SI group that also demonstrated the highest fluoride recharge ability. Hence, the combination of mesoporous silica and calcium aluminate cement is promising as a new type of filler without fluoride incorporation as a dental restorative material for preventing dental caries.

The current study is the first report to demonstrate that a new formulation of resin-based pit and fissure sealant containing a combination of synthesized mesoporous silica and calcium aluminate cement is a promising material that can recharge with fluoride and neutralize lactic acid. This material could protect tooth structure by enhancing tooth remineralization and preventing secondary caries formation.

\section{ACKNOWLEDGMENTS}

This study was supported by a Chulalongkorn University graduate scholarship to commemorate the 72nd anniversary of his Majesty the King Bhumibol Adulyadej, the 90th anniversary of Chulalongkorn University fund (Ratchadaphiseksomphot endowment fund), Ratchadaphiseksomphot endowment under outstanding research performance program, and the Faculty of Dentistry, Chulalongkorn University fund. The authors gratefully thank Dr. P.L. FAN for his valuable suggestions. We also thank Dr. Kevin TOMPKINS for critical review of the manuscript.

\section{REFERENCES}

1) Chen XX, Liu XG. Clinical comparison of Fuji VII and a resin sealant in children at high and low risk of caries. Dent Mater J 2013; 32: 512-518.

2) Haznedaroğlu E, Güner Ş, Duman C, Menteş A. A 48-month randomized controlled trial of caries prevention effect of a one-time application of glass ionomer sealant versus resin sealant. Dent Mater J 2016; 35: 532-538.

3) Rock WP, Foulkes EE, Perry H, Smith AJ. A comparative study of fluoride-releasing composite resin and glass ionomer materials used as fissure sealants. J Dent 1996; 24: 275-280.

4) Cooley RL, McCourt JW, Huddleston AM, Casmedes HP. Evaluation of a fluoride-containing sealant by SEM, microleakage, and fluoride release. Pediatr Dent 1990; 12: 38-42.

5) Preston AJ, Agalamanyi EA, Higham SM, Mair LH. The recharge of esthetic dental restorative materials with fluoride in vitro - two years' results. Dent Mater 2003; 19: 32-37.

6) Koga H, Kameyama A, Matsukubo T, Hirai Y, Takaesu Y. Comparison of short-term in vitro fluoride release and recharge from four different types of pit-and-fissure sealants. Bull Tokyo Dent Coll 2004; 45: 173-179.

7) Han L, Cv E, Li M, Niwano K, Ab N, Okamoto A, Honda N, Iwaku M. Effect of fluoride mouth rinse on fluoride releasing and recharging from aesthetic dental materials. Dent Mater J 2002; 21: 285-295.

8) Loof J, Engqvist H, Ahnfelt NO, Lindqvist K, Hermansson L. Mechanical properties of a permanent dental restorative material based on calcium aluminate. J Mater Sci Mater Med 2003; 14: 1033-1037.

9) Sakhare N, Lunge S, Rayalu S, Bakardjiva S, Subrt J, Devotta S, Labhsetwar N. Defluoridation of water using calcium aluminate material. Chem Eng J 2012; 203: 406-414.

10) Gupta AK, Ayoob S. Fluoride in drinking water: Status, issues, and solutions. Boca Raton: CRC Press; 2016. p. 93.

11) Slowing II, Vivero-Escoto JL, Wu CW, Lin VS. Mesoporous silica nanoparticles as controlled release drug delivery and gene transfection carriers. Adv Drug Deliv Rev 2008; 60: 1278-1288.

12) Kalapathy U, Proctor A, Shultz J. A simple method for production of pure silica from rice hull ash. Bioresour Technol 2000; 73: 257-262.

13) Nicholson JW, Aggarwal A, Czarnecka B, Limanowska-Shaw $\mathrm{H}$. The rate of change of $\mathrm{pH}$ of lactic acid exposed to glassionomer dental cements. Biomaterials 2000; 21: 1989-1993.

14) Yang SY, Piao YZ, Kim SM, Lee YK, Kim KN, Kim KM. Acid neutralizing, mechanical and physical properties of pit and fissure sealants containing melt-derived 45S5 bioactive glass. Dent Mater 2013; 29: 1228-1235.

15) Shimazu K, Ogata K, Karibe H. Evaluation of the ionreleasing and recharging abilities of a resin-based fissure sealant containing S-PRG filler. Dent Mater J 2011; 30: 923927.

16) Hicks MJ, Flaitz CM, Garcia-Godoy F. Fluoride-releasing sealant and caries-like enamel lesion formation in vitro. J Clin Pediatr Dent 2000; 24: 215-219.

17) Jensen ME, Wefel JS, Triolo PT, Hammesfahr PD. Effects of a fluoride-releasing fissure sealant on artificial enamel caries. Am J Dent 1990; 3: 75-78.

18) Chacko $Y$, Lakshminarayanan L. pH stabilizing properties of a posterior light cured resin composite: an in vivo study. Oper Dent 2001; 26: 219-222.

19) Kuşgöz A, Tüzüner T, Ülker M, Kemer B, Saray O. Conversion degree, microhardness, microleakage and fluoride release of different fissure sealants. J Mech Behav Biomed Mater 2010; 3: 594-599.

20) Ripa LW. Sealants revisted: an update of the effectiveness of pit-and-fissure sealants. Caries Res 1993; 27 Suppl 1: 77-82. 
21) Ganesh M, Shobha T. Comparative evaluation of the marginal sealing ability of Fuji VII and Concise as pit and fissure sealants. J Contemp Dent Pract 2007; 8: 10-18.

22) Kantovitz KR, Pascon FM, Correr GM, Borges AF, Uchôa MN, Puppin-Rontani RM. Inhibition of mineral loss at the enamel/sealant interface of fissures sealed with fluorideand non-fluoride containing dental materials in vitro. Acta Odontol Scand 2006; 64: 376-383.

23) Takahashi K, Emilson CG, Birkhed D. Fluoride release in vitro from various glass ionomer cements and resin composites after exposure to NaF solutions. Dent Mater 1993; 9: 350354.

24) Young A, von der Fehr FR, Sønju T, Nordbø H. Fluoride release and uptake in vitro from a composite resin and two orthodontic adhesives. Acta Odontol Scand 1996; 54: 223228.

25) Billington RW, Hadley PC, Williams JA, Pearson GJ. Kinetics of fluoride release from zinc oxide-based cements. Biomaterials 2001; 22: 2507-2513.

26) Attar N, Turgut MD. Fluoride release and uptake capacities of fluoride-releasing restorative materials. Oper Dent 2003; 28: 395-402.

27) De Moor RJ, Verbeeck RM, De Maeyer EA. Fluoride release profiles of restorative glass ionomer formulations. Dent Mater 1996; 12: 88-95.

28) 3M ESPE. Materials safety data sheet (MSDS): Concise $^{\mathrm{TM}}$ light cured white sealant resin. 2016.

29) Wasson EA, Nicholson JW. New aspects of the setting of glass-ionomer cements. J Dent Res 1993; 72: 481-483.

30) Wilson AD. Secondary reactions in glass-ionomer cements. J Mater Sci Lett 1996; 15: 275-276.

31) Tay FR, Pashley EL, Huang C, Hashimoto M, Sano H, Smales RJ, Pashley DH. The glass-ionomer phase in resin-based restorative materials. J Dent Res 2001; 80: 1808-1812.

32) Dhondt CL, De Maeyer EA, Verbeeck RM. Fluoride release from glass ionomer activated with fluoride solutions. J Dent Res 2001; 80: 1402-1406.

33) International Standards Organization. ISO 6872. Dentistry-
Ceramic materials. Geneve: International Organization for Standardization 2015

34) Milleding P, Wennerberg A, Alaeddin S, Karlsson S, Simon E. Surface corrosion of dental ceramics in vitro. Biomaterials 1999; 20: 733-746.

35) Xu X, Burgess JO. Compressive strength, fluoride release and recharge of fluoride-releasing materials. Biomaterials 2003; 24: 2451-2461.

36) Kavaloglu Cildir S, Sandalli N. Compressive strength, surface roughness, fluoride release and recharge of four new fluoridereleasing fissure sealants. Dent Mater J 2007; 26: 335-341.

37) Dionysopoulos D, Koliniotou-Koumpia E, HelvatzoglouAntoniades M, Kotsanos N. Fluoride release and recharge abilities of contemporary fluoride-containing restorative materials and dental adhesives. Dent Mater J 2013; 32: 296304.

38) Alothman ZA. A review: Fundamental aspects of silicate mesoporous materials. Materials 2012; 5: 2874-2902.

39) Geirsson J, Thompson JY, Bayne SC. Porosity evaluation and pore size distribution of a novel directly placed ceramic restorative material. Dent Mater 2004; 20: 987-995.

40) El-Kalla IH, Garcia-Godoy F. Mechanical properties of compomer restorative materials. Oper Dent 1999; 24: 2-8.

41) Matsuya S, Matsuya Y, Yamamoto Y, Yamane M. Erosion process of a glass ionomer cement in organic acids. Dent Mater J 1984; 3: 210-219.

42) Nicholson JW, Czarnecka B, Limanowska-Shaw H. A preliminary study of the effect of glass-ionomer and related dental cements on the $\mathrm{pH}$ of lactic acid storage solutions. Biomaterials 1999; 20: 155-158.

43) Kaga M, Kakuda S, Ida Y, Toshima H, Hashimoto M, Endo K, Sano H. Inhibition of enamel demineralization by buffering effect of S-PRG filler-containing dental sealant. Eur J Oral Sci 2014; 122: 78-83.

44) Loof J, Svahn F, Jarmar T, Engqvist H, Pameijer CH. A comparative study of the bioactivity of three materials for dental applications. Dent Mater 2008; 24: 653-659. 